\title{
Merkel cell polyomavirus detected in head and neck carcinomas from Chile
}

\author{
Juan P. Muñoz ${ }^{1 \dagger}$, Rancés Blanco ${ }^{2 \dagger}$, Julio C. Osorio ${ }^{2 \dagger}$, Carolina Olivaa ${ }^{2 \dagger}$, María José Diaz ${ }^{2}$, Diego Carrillo-Beltrán ${ }^{2}$, \\ Rebeca Aguayo ${ }^{3}$, Andrés Castillo4, Julio C. Tapia ${ }^{5}$, Gloria M. Calaf ${ }^{1,6}$, Aldo Gaggero ${ }^{2}$ and Francisco Aguayo ${ }^{1,2,7^{*}}$ (D)
}

\begin{abstract}
Background: The role of human polyomaviruses (HPyVs) in epithelial tumors such as head and neck carcinomas (HNSCCS) including oral and oropharyngeal carcinomas has not been established. In this study, we evaluated for the first time the presence of Merkel cell polyomavirus (MCPyV), BK human polyomavirus (BKPyV), and JC human polyomavirus (JCPyV) in HNSCCS from Chilean subjects.

Methods: One hundred and twenty HNSCCs were analyzed for the presence of MCPyV, BKPyV and JCPyV using real-time polymerase chain reaction procedures. In addition, 54 oral brushes from age- and sex-paired subjects were analyzed.

Results: Of the total of 120 HNSCCs, 15 were positive for MCPyV (12.5\%). Only one case was positive for BKPyV $(0.8 \%)$ and none for JCPyV (0\%). In subjects without cancer, only one case (1.8\%) resulted positive for MCPyV and none for JCPyV and BKPyV. MCPyV was associated with HNSCCs ( $p=0.0239 ; \mathrm{OR}=7.571 ; 95 \%$ Cl: 1.192-81.46). No association was found between age $(p=0.1996)$, gender $(p=0.7111)$ or differentiation status $(p>0.9999)$ and MCPyV presence in HNSCCS.

Conclusions: MCPyVs were detected in HNSCCs from Chilean patients and were not detected in oral brushes from patients without cancer. More studies are warranted for defining an etiological role and clinical/molecular consequences of these viruses in HNSCCS.
\end{abstract}

Keywords: Cancer, Head and neck, Polyomavirus

\section{Introduction}

Human polyomaviruses (HPyVs) are small DNA viruses classified into the Polyomaviridae family and are widely distributed in human population [1]. BKPyV and JCPyV were discovered in 1971 . In the last 15 years, mainly due to the development of new high-throughput sequencing techniques, other twelve HPyVs have been discovered (MCPyV, KIPyV, WUPyV, TSPyV, HPyV6, HPyV7, HPyV9, HPyV10, HPyV12, STLPyV, NJPyV and LIPyV) $[2,3]$. HPyV infection usually occurs early in life through a fecal-oral transmission mechanism and persists for the lifetime of the infected subject. In natural hosts, these

\footnotetext{
* Correspondence: faguayo@med.uchile.cl

†Juan P. Muñoz, Rancés Blanco, Julio C. Osorio and Carolina Oliva contributed equally to this work.

${ }^{1}$ Instituto de Alta Investigación (IAI), Universidad de Tarapaca, Arica, Chile ${ }^{2}$ Programa de Virología, Instituto de Ciencias Biomédicas (ICBM), Faculty of Medicine, Universidad de Chile, Santiago, Chile

Full list of author information is available at the end of the article
}

viruses establish a productive infection, although in heterologous non-permissive hosts, the virus establishes latency with potential integration into the host genome [2]. HPyVs are very ubiquitous in nature and their association with some pathologies, cancer in particular, is under intensive investigation [4]. All members of the $\mathrm{HPyV}$ family encode the Large and small $\mathrm{T}$-antigens that exhibit variable oncogenic potential in in vitro and animal models oncogenic protein $\mathrm{T}$-antigen. In some cases, these proteins can inactivate $\mathrm{p} 53$, members of the $\mathrm{pRb}$ protein family and other cellular factors diminishing apoptosis and deregulating the cell cycle [5]. In addition, $\mathrm{T}$-antigen interacts with beta-catenin, enhancing the transcription of the c-myc promoter [6]. However, out of the HPyV family, only MCPyV has been causally associated with human cancer, specifically Merkel cell carcinoma, a very rare skin cancer with a neuroendocrine origin $[7,8]$. The role of other HPyVs such as BKPyV

(c) The Author(s). 2020 Open Access This article is distributed under the terms of the Creative Commons Attribution 4.0 International License (http://creativecommons.org/licenses/by/4.0/), which permits unrestricted use, distribution, and reproduction in any medium, provided you give appropriate credit to the original author(s) and the source, provide a link to the Creative Commons license, and indicate if changes were made. The Creative Commons Public Domain Dedication waiver (http://creativecommons.org/publicdomain/zero/1.0/) applies to the data made available in this article, unless otherwise stated. 
and JCPyV in human cancer remains highly controversial and unclear [9-11].

Head and neck cancers (HNCs) comprise different malignancies which include lip, oral cavity, nasopharynx, oropharynx, hypopharynx, pharynx and larynx cancer [12]. The worldwide incidence of these malignant tumors is more than 550,000 cases with 300,000 deaths per year with a male to female ratio that ranges from 2:1 to $4: 1$ [13]. Approximately $90 \%$ of HNCs are squamous cell carcinomas (HNSCCs), the sixth leading cancer by incidence worldwide [12]. In Chile, it has been estimated that lip and oral cancer incidence is 1.3 cases per 100 , 000 inhabitants; oropharynx and hypopharynx is 0.5 cases per 100,000 inhabitants, and larynx is 1.2 cases per 100,000 inhabitants [14].

HNSCC is strongly associated with certain environmental and lifestyle risk factors such as tobacco smoking and alcohol consumption [15]. In addition, infection with high-risk human papillomavirus (HR-HPV), especially HPV type 16 , is a risk factor for oropharyngeal tumors that involve the tonsils or the base of the tongue [16], while infection with the Epstein-Barr virus (EBV) is a risk factor for nasopharyngeal and salivary gland cancers [17]. In fact, our group previously reported that $11 \%$ of oral carcinomas were positive for HR-HPV in Chilean patients. Moreover, the most frequent HPV genotype found in this study was HPV16, a high-risk HPV type [18]. It is unknown whether other DNA viruses are involved in the development of HNSCC. Therefore, in this study we evaluated the prevalence of $\mathrm{MCPyV}, \mathrm{BKPyV}$ and JCPyV in oral and oropharyngeal carcinomas from Chilean patients for the first time.

\section{Materials and methods}

\section{Clinical specimens}

We conducted an analysis of 135 oral and oropharyngeal carcinomas from Chilean patients and 54 oral brushes from sex- and age-paired healthy Chilean subjects. Tumor samples were collected at Instituto Nacional del Cancer (INC) "Caupolicán Pardo"; Facultad de Odontología, Universidad de Chile; and "San José" Hospital (Santiago, Chile). All cases were confirmed by histological analyses, of which 99 corresponded to formalinfixed and paraffin-embedded (FFPE) specimens obtained between 2003 and 2014 and 36 frozen tissues stored at $-80^{\circ} \mathrm{C}$, obtained between 2014 and 2016. The 54 oral brushing samples were collected during 2016, from patients without neoplasia who were treated for minor dental problems in CESFAM "El Roble" (La Pintana, Santiago). The patients provided their written informed consent to participate in the study, which was approved by the respective ethics committee of each institution. Frozen tissues with a weight $<1 \mathrm{~g}$ and paraffin tissue sections with $<10 \%$ of tumor cells were excluded. This study was approved by the Ethical Committee Board of the Faculty of Medicine, University of Chile (Number 071-2011).

\section{DNA extraction}

Paraffin tissue sections were incubated with digestion buffer $(10 \mathrm{mM}$ Tris- $\mathrm{HCl} \mathrm{pH} 7.4,0.5 \mathrm{mg} / \mathrm{mL}$ proteinase $\mathrm{K}$ and $0.4 \%$ Tween 20 ) at $37^{\circ} \mathrm{C}$ overnight. Afterwards, the samples were incubated for $10 \mathrm{~min}$ at $95^{\circ} \mathrm{C}$, centrifuged for $2 \mathrm{~min}$ at $14,000 \mathrm{rpm}$ and immediately placed on ice. After centrifugation, the aqueous phase was transferred to a new tube for analysis.

\section{Real-time polymerase chain reaction (qPCR)}

$\mathrm{BKPyV}$ detection was conducted using qPCR with an intercalating dye format as previously reported [19]. Briefly, a $127 \mathrm{bp}$ fragment of the BKPyV genome was amplified with the following BK127-F and BK127-R primers: BK127-F: 5'-GCA GCT CCC AAA AAG CCA AA-3' and BK127-R: 5'-CTG GGT TTA GGA AGC ATT CTA-3'. The $20 \mu \mathrm{L}$ final volume reactions contained 1X LightCycler ${ }^{\circ}$ FastStart DNA Master SYBR Green I (Roche Diagnostics, Indianapolis, IN, USA), $0.5 \mu \mathrm{M}$ of each primer, $3.0 \mu \mathrm{M} \mathrm{MgCl} 2$ and $5 \mu \mathrm{L}$ of DNA template. The PCR reaction was run for 40 cycles as follows: denaturation at $94{ }^{\circ} \mathrm{C}$ for $10 \mathrm{~s}$, annealing at $62^{\circ} \mathrm{C}$ for $10 \mathrm{~s}$ and extension at $72{ }^{\circ} \mathrm{C}$ for $10 \mathrm{~s}$, with an initial denaturation at $95^{\circ} \mathrm{C}$ for $15 \mathrm{~min}$ and final extension at $72{ }^{\circ} \mathrm{C}$ for $10 \mathrm{~min}$. The amplification products were subjected to a melting profile and the specific product was characterized according to its Tm. JCPyV was detected using qPCR with JE3 primers and a JE3 probe set (JE3(Mad-1) F: $5^{\prime}$-ATG TTT GCC AGT GAT GAT GAA AA-3', JE3-(Mad-1) R: 5' -GGA AAG TCT TTA GGG TCT TCT ACC TTT-3' and JE3-(Mad-1) Probe 5'FAM-AGG ATC CCA ACA CTC TAC CCC ACC TAA AAA GA-BHQ1-3') according to a previously described protocol [20] The PCR reaction contained 1X Brilliant ${ }^{\circ}$ II QRT-PCR Master Mix (Agilent Technologies Santa Clara, CA, USA), $0.5 \mu \mathrm{M}$ of each primer, $0.15 \mu \mathrm{M}$ of probe and $5 \mu \mathrm{L}$ of DNA in a total volume of $25 \mu \mathrm{L}$. The amplification conditions were as follows: $95^{\circ} \mathrm{C}$ for 10 min, followed by 50 cycles with denaturation at $95^{\circ} \mathrm{C}$ for $15 \mathrm{~s}$ and annealing/extension at $60^{\circ} \mathrm{C}$ for $1 \mathrm{~min}$. The $\mathrm{MCPyV}$ detection was conducted using $\mathrm{qPCR}$ with a TaqMan probe (FAM-TCCTTCTCAGCGTCCCAG GCTTCA-TAMRA) in LightCycler 2.0 (Roche Diagnostics, Indianapolis, IN, USA), as previously reported. Briefly, a 146 fragment of the TAg gene was amplified with the primers: LT1-F: 5' - CCACAGCCAGAGCT CTTCCT-3' and LT1-R: 5' - TGGTGGTCTCCTCT CTGCTACTG-3'. The PCR reaction contained 1X TaqMan Universal PCR Master Mix (Bioline Ltd., London, $\mathrm{UK}), 0.9 \mu \mathrm{M}$ of each primer and $0.5 \mu \mathrm{M}$ of TaqMan 
probe and $5 \mu \mathrm{L}$ of DNA in a total volume of $20 \mu \mathrm{L}$. The PCR reaction was run as follows: $50^{\circ} \mathrm{C}$ for $2 \mathrm{~min}, 95^{\circ} \mathrm{C}$ for $10 \mathrm{~min}$, followed by 45 cycles with denaturation at $95^{\circ} \mathrm{C}$ for $5 \mathrm{~s}$, annealing at $60^{\circ} \mathrm{C}$ for $1 \mathrm{~min}$ and extension at $40{ }^{\circ} \mathrm{C}$ for $30 \mathrm{~s}$.

\section{Statistical analysis}

For categorical variables, the frequency tables were ana-

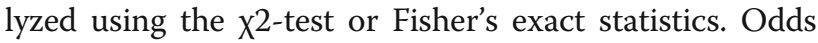
ratio (OR) and their 95\% confidence intervals (95\% CI) were calculated where appropriate, using the exact method. All statistical tests were performed as two-sided and considered significant at $p$-value $<0.05$. Statistical analyses were run using the GraphPad Prism 8 software.

\section{Results}

\section{Clinical-pathological features}

We analyzed the presence of MCPyV, BKPyV and JCPyV in Chilean patients diagnosed with oral cavity and oropharyngeal carcinomas through a retrospective study. Of the 99 FFPE samples, 15 were excluded because they tested negative for the $\beta$-globin fragment (internal control) or not enough tissue material was available. The 36 frozen tissue specimens amplified for the same fragment. Table 1 shows the clinicopathological characteristics of the 120 patients included in this study. The $51.4 \%$ of patients corresponds to women and $48.6 \%$ to men, with an average age of 63.6 years (range 30-97 years). The majority of tumor samples $(55.9 \%)$ were classified as well differentiated grade.

Table 1 Clinicopathological features of HNSCC patients

\begin{tabular}{ll}
\hline Variable & $\begin{array}{l}\text { HNSCC cases } \\
(n=120) \\
\text { number (percentages) }\end{array}$ \\
\hline Gender & $37(51.4)$ \\
Female & $35(48.6)$ \\
Male & 48 \\
Unknown & \\
Age & $31(47.7)$ \\
$<65$ yr & $34(52.3)$ \\
$\geq 65 \mathrm{yr}$ & 55 \\
Unknown & 63.6 \\
Average (yr) & $30-97$ \\
Range (yr) & \\
Tumor differentiation & $19(55.9)$ \\
Well & $12(35.3)$ \\
Moderate & $3(8.8)$ \\
Poorly & 86 \\
Unknown &
\end{tabular}

Legend. HNSCC Head and Neck squamous cell carcinoma; yr years
Table 2 Presence of HPyVs in HNSCCS and oral brushes from Chilean patients

\begin{tabular}{llll}
\hline Cases (total) & MCPyV & JCPyV & BKPyV \\
\hline Oral brushes (54) & $1(1.8)$ & $0(0)$ & $0(0)$ \\
HNSCCS (120) & $15(12.5)$ & $1(0.8)$ & $0(0)$ \\
\hline
\end{tabular}

Legend. HNSCC Head and Neck squamous cell carcinoma; MCPyV Merkel cell polyomavirus; JCPyV JC polyomavirus; BKPyV BK polyomavirus

\section{HPyVs presence in head and neck carcinomas}

Fifteen of the HNSCCs were positive for MCPyV (12.5\%), of which $9 / 15(60.0 \%)$ and $6 / 15$ (40.0\%) correspond to FFPE and frozen samples, respectively. Additionally, $1(1,8 \%)$ HNSCC was positive for JCPyV and none for BKPyV. In contrast, MCPyV was only detected in $1 / 54(1.8 \%)$ of healthy patients. JCPyV and BKPyV were negative for this group (Table 2). The difference of MCPyV presence between HNSCCs and oral brushes was statistically significant ( $p=0.0239 ; \mathrm{OR}=7.571 ; 95 \%$ CI: 1.192-81.46) (Table 3). Among positive cases, the infection with MCPyV was mostly detected in women (5/8 cases; $62.5 \%$ ), in patients $\geq 65$ years $(5 / 6 ; 83.3 \%)$ as well as in tumors displaying moderate and well differentiated grades $(2 / 2 ; 100 \%)$. However, no statistically significant differences were found between age $(p=0.1996)$, gender $(p=0.7111)$ or tumor differentiation $(p>0.9999)$ and $\mathrm{MCPyV}$ presence in HNSCCs.

\section{Discussion}

In this study, we found that MCPyV is frequently present in HNSCCs from Chilean patients. Our data report the occurrence of $\mathrm{MCPyV}$ infection in $12.5 \%$ of HNSCCs samples. In contrast, the presence of MCPyV was only detected in $1.8 \%$ of healthy subjects. Similarly, Mohebbi et al. published the MCPyV positivity in $16 \%$ of HNSCCs from Iranian patients vs. $2 \%$ in the control group [21]. However, Tanio et al. reported a low MCPyV prevalence of $4.0 \%$ in oral cavity carcinoma from Japanese patients [22], while Hamiter et al. described that $28.6 \%$ of squamous cell carcinoma of the tongue were positive for MCPyV DNA sequences in North American population [23]. Of interest, in the Czech population, MCPyV was positive in $35.7 \%$ of squamous cell tonsillar

Table 3 MCPYV in HNSCCS and oral brushes from Chilean patients

\begin{tabular}{|c|c|c|c|c|}
\hline \multirow[t]{4}{*}{ Variable } & \multicolumn{2}{|l|}{ MCPyV } & \multirow[t]{3}{*}{ OR (95\% Cl) } & \multirow{4}{*}{$\begin{array}{l}P \text { - } \\
\text { value }\end{array}$} \\
\hline & Positive & Negative & & \\
\hline & $(n=16)$ & $(n=158)$ & & \\
\hline & \multicolumn{3}{|l|}{$\begin{array}{l}\text { number } \\
\text { (percentage) }\end{array}$} & \\
\hline $\begin{array}{l}\text { Oral } \\
\text { brushes }\end{array}$ & $1(1.85)$ & $53(98.15)$ & 7.571 (1.192-81.46) & 0.0239 \\
\hline HNSCCS & $15(12.5)$ & $105(87.5)$ & & \\
\hline
\end{tabular}

Legend. OR Odds Ratio; Cl Confidence Interval 
carcinomas and in $10.2 \%$ of non-malignant tissues [24]. No associations of MCPyV and clinicopathological features of HNSCC patients were evidenced. In previous studies, no significant difference between $\mathrm{MCPyV}$ positivity with age, gender, type of HNSCC, and cancer stages was reported. However, MCPyV DNA viral load was associated with advanced stages of HNSCCs [21]. On the contrary, the presence of $\mathrm{MCPyV}$ in oral tongue SCC was associated with lower recurrence rates [23]. In this regard, the relation of MCPyV presence in HNSCCs with the biological behavior of these malignancies remains controversial. A limitation of our study was the extensive lack of clinical information. This restricted the establishment of better associations between the presence of MCPyV and clinicopathological features of cancer patients, which need to be addressed in further studies. In the case of the virus BKPyV, only one infected sample $(0.8 \%)$ of HNSCCs was detected, similar to a previous report conducted by Poluschkin et al. in which $1.2 \%$ of oral carcinoma cases from Finnish patients was considered positive [25]. In contrast, two different studies conducted in Lublin (Poland) showed the presence of BKPyV DNA in 18.5 and $17.7 \%$ of patients with oropharyngeal and oral carcinomas, respectively, and only in $3.3 \%$ of the control group [26]. This fact encouraged consideration of the role of BKV virus in the development of oral squamous cell carcinoma [26, 27]. Moreover, in the same population, Drop et al. found BKPyV DNA in $17.2 \%(11 / 64)$ of HNSCCs including oropharynx (14.3\%), larynx (18.2\%) and oral cavity (21.4\%) [28], evidencing a preferential presence of BKPyV in HNSCCs patients from this country. In addition, we found that oral and oropharyngeal samples did not show JCPyV DNA amplification, similar to a previous report conducted by Polz et al. in oral carcinomas [26]. Nevertheless, Poluschkin et al. published infection with JCPyV in 37\% of HNSCCs, including lip (80\%), larynx (67\%) and oral cavity (59\%), but not in oropharyngeal carcinomas [25]. Monaco et al. reported the presence of JCPyV DNA in about 35\% of tonsil tissue from both immunocompetent children and healthy adult donors, providing evidence concerning the site of infection [29]. Interestingly, Kutsuna et al. found more than 200 copies/ $\mu$ g of JCV-targeting $\mathrm{T}$ antigen in 92.3\% of tongue squamous carcinomas, which was significantly increased when compared with dysplastic tongue epithelium and glossitis [30], suggesting a potential association of JCPyV load with this type of cancer. In the present study, the number of samples infected with MCPyV, BKPyV and JCPyV in HNSCCs from Chilean patients was generally found to be low when compared with other populations around the world. Regarding MCPyV, it is the only polyomavirus clearly associated with a human cancer, Merkel cell carcinoma (MCC), which mainly occurs in Caucasians as well as in populations located in equatorial proximity [7]. Concerning BKPyV and JCPyV, they were associated with prostatic and colorectal cancer, respectively [31, 32]. Of note, the existence of various genotypes linked to the geographical origin of the infected individuals has been reported [33]. These population differences are important because of the differential risk of developing cancer. In this sense, the evaluation of other risk factors implicated in head and neck carcinogenesis are of great significance.

The clinical and molecular consequences of MCPyV presence in HNSCCS from Chilean patients are unknown. Previously, we reported the presence of high-risk HPV in a subset of oral carcinomas from Chilean patients [18]. Thus, a possible collaboration between HPV and MCPyV in head and neck cancer is an interesting point that needs to be investigated in the future, as previously reported in laryngeal cancer [34].

To summarize, in this study we evaluated the prevalence of MCPyV, BKPyV and JCPyV in HNSCCs from Chilean patients for the first time. MCPyV was increased in HNSCCs when compared with BKPyV and JCPyV, suggesting an association of $\mathrm{MCPyV}$ infection with these malignant tumors. However, no relation between $\mathrm{MCPyV}$ infection and age, gender, tumor localization or differentiation status was evidenced.

\section{Conclusions}

MCPyV is present in HNSCCs from Chilean patients and is almost absent in oral brushes from healthy subjects. Further studies are strongly necessary in order to elucidate a potential etiological role for this virus in the development and/or progression of this cancer.

\section{Abbreviations}

BKPyV: BK human polyomavirus; Cl: Confidence intervals; EBV: Epstein-Barr virus; FFPE: Formalin-fixed and paraffin-embedded; HNCs: Head and neck cancers; HNSCCs: Head and neck carcinomas; HPyVs: Human polyomaviruses; HR-HPV: High-risk human papillomavirus; JCPyV: JC human polyomavirus; MCC: Merkel cell carcinoma; MCPyV: Merkel cell polyomavirus; OR: Odds ratio; qPCR: Quantitative polymerase chain reaction

\section{Acknowledgments \\ Not applicable.}

\section{Authors' contributions}

JPM, RB, JCO, CO contributed with statistical analysis, data interpretation and manuscript writing; MJD, DCB contributed with analysis of clinical samples and data interpretation; RA contributed with clinical specimens and data collection; AC, GMC, AG: contributed with data interpretation and discussion; FA contributed with the design of this study, reagents, data interpretation and manuscript writing.

\section{Funding}

This study was supported by FONDECYT Grants 1120248/1161219 (FA), FONDECYT Postdoctoral Grants 3190723 (RB) and 3190744 (JPM), CONICYT scholarship for doctoral degree 21180901 (DCB)/21181116 (CO) and CONICYT-FONDAP 15130011 (FA). 


\section{Availability of data and materials}

The datasets used and/or analyzed during the current study are available from the corresponding author on reasonable request.

\section{Ethics approval and consent to participate}

The proposal of the study was ethically approved by the ethics committee of Faculty of Medicine, University of Chile (August 26, 2011).

\section{Consent for publication}

Not applicable.

\section{Competing interests}

The authors declare that they have no competing interests.

\section{Author details}

${ }^{1}$ Instituto de Alta Investigación (IAI), Universidad de Tarapaca, Arica, Chile. ${ }^{2}$ Programa de Virología, Instituto de Ciencias Biomédicas (ICBM), Faculty of Medicine, Universidad de Chile, Santiago, Chile. ${ }^{3}$ Centro de Salud Familiar "El Roble", Municipalidad de La Pintana, Santiago, Chile. ${ }^{4}$ Department of Biology, Faculty of Natural and Exact Sciences at Universidad del Valle, Cali, Colombia. ${ }^{5}$ Departamento de Oncología Básico Clínica, Faculty of Medicine, University of Chile, Santiago, Chile. ${ }^{6}$ Center for Radiological Research, Columbia University Medical Center, New York, NY, USA. ${ }^{7}$ Advanced Center for Chronic diseases (ACCDiS), Universidad de Chile, Santiago, Chile.

Received: 8 January 2020 Accepted: 16 January 2020

Published online: 28 January 2020

\section{References}

1. Dalianis T, Hirsch HH. Human polyomaviruses in disease and cancer. Virology. 2013;437(2):63-72

2. Bhattacharjee $\mathrm{S}$, Chattaraj S. Entry, infection, replication, and egress of human polyomaviruses: an update. Can J Microbiol. 2017:63(3):193-211.

3. Prado JCM, Monezi TA, Amorim AT, Lino V, Paladino A, Boccardo E. Human polyomaviruses and cancer: an overview. Clinics (Sao Paulo). 2018;73(suppl 1):e558s

4. Mui UN, Haley CT, Tyring SK. Viral oncology: molecular biology and pathogenesis. J Clin Med. 2017;6:12

5. Baez CF, Brandão Varella R, Villani S, Delbue S. Human Polyomaviruses: the Battle of large and small tumor antigens. Virology (Auckl). 2017;8:1-12.

6. Enam S, Del Valle L, Lara C, Gan DD, Ortiz-Hidalgo C, Palazzo JP, et al. Association of human polyomavirus JCV with colon cancer: evidence for interaction of viral T-antigen and beta-catenin. Cancer Res. 2002;62(23): 7093-101.

7. Spurgeon ME, Lambert PF. Merkel cell polyomavirus: a newly discovered human virus with oncogenic potential. Virology. 2013:435(1):118-30.

8. Amaral T, Leiter U, Garbe C. Merkel cell carcinoma: epidemiology, pathogenesis, diagnosis and therapy. Rev Endocr Metab Disord. 2017:18(4):517-32.

9. Tseng CE, Yeh CM, Fang CY, Shay J, Chen PL, Lin MC, et al. Detection of human JCPyV and BKPyV in diffuse large B-cell lymphoma of the Gl tract. Eur J Clin Microbiol Infect Dis. 2014;33(4):665-72.

10. Delbue S, Comar M, Ferrante P. Review on the role of the human Polyomavirus JC in the development of tumors. Infect Agent Cancer. 2017; 12:10

11. Keller EX, Delbue S, Tognon M, Provenzano M. Polyomavirus BK and prostate cancer: a complex interaction of potential clinical relevance. Rev Med Virol. 2015:25(6):366-78

12. Perdomo S, Martin Roa G, Brennan P, Forman D, Sierra MS. Head and neck cancer burden and preventive measures in central and South America. Cancer Epidemiol. 2016;44(Suppl 1):S43-52.

13. Fitzmaurice C, Allen C, Barber RM, Barregard L, Bhutta ZA, Brenner H, et al. Global, regional, and national cancer incidence, mortality, years of life lost, years lived with disability, and disability-adjusted life-years for 32 cancer groups, 1990 to 2015: a systematic analysis for the global burden of disease study global burden of disease Cancer collaboration. JAMA Oncol. 2017;3(4):524-48.

14. Ferlay J, Steliarova-Foucher E, Lortet-Tieulent J, Rosso S, Coebergh JW Comber $\mathrm{H}$, et al. Cancer incidence and mortality patterns in Europe: estimates for 40 countries in 2012. Eur J Cancer 2013:49(6):1374-403.

15. Dhull AK, Atri R, Dhankhar R, Chauhan AK, Kaushal V. Major risk factors in head and neck Cancer: a retrospective analysis of 12-year experiences. World J Oncol. 2018;9(3):80-4.
16. Chaturvedi AK, Engels EA, Pfeiffer RM, Hernandez BY, Xiao W, Kim E, et al. Human papillomavirus and rising oropharyngeal cancer incidence in the United States. J Clin Oncol. 2011;29(32):4294-301.

17. Chien YC, Chen JY, Liu MY, Yang HI, Hsu MM, Chen CJ, et al. Serologic markers of Epstein-Barr virus infection and nasopharyngeal carcinoma in Taiwanese men. N Engl J Med. 2001;345(26):1877-82.

18. Reyes M, Rojas-Alcayaga G, Pennacchiotti G, Carrillo D, Muñoz JP, Peña N, et al. Human papillomavirus infection in oral squamous cell carcinomas from Chilean patients. Exp Mol Pathol. 2015;99(1):95-9.

19. Rodriguez H, Levican J, Munoz JP, Carrillo D, Acevedo ML, Gaggero A, et al. Viral infections in prostate carcinomas in Chilean patients. Infect Agent Cancer. 2015;10:27

20. Pal A, Sirota L, Maudru T, Peden K, Lewis AM Jr. Real-time, quantitative PCR assays for the detection of virus-specific DNA in samples with mixed populations of polyomaviruses. J Virol Methods. 2006;135(1):32-42.

21. Mohebbi E, Noormohamadi Z, Sadeghi-Rad H, Sadeghi F, Yahyapour Y, Vaziri F, et al. Low viral load of Merkel cell polyomavirus in Iranian patients with head and neck squamous cell carcinoma: is it clinically important? J Med Virol. 2018;90(2):344-50.

22. Tanio S, Matsushita M, Kuwamoto S, Horie Y, Kodani I, Murakami I, et al. Low prevalence of Merkel cell polyomavirus with low viral loads in oral and maxillofacial tumours or tumour-like lesions from immunocompetent patients: absence of Merkel cell polyomavirus-associated neoplasms. Mol Clin Oncol. 2015:3(6):1301-6.

23. Hamiter M, Asarkar A, Rogers D, Moore-Medlin T, McClure G, Ma X, et al. A pilot study of Merkel cell polyomavirus in squamous cell carcinoma of the tongue. Oral Oncol. 2017;74:111-4.

24. Saláková M, Košlabová E, Vojtěchová Z, Tachezy R, Šroller V. Detection of human polyomaviruses MCPyV, HPyV6, and HPyV7 in malignant and nonmalignant tonsillar tissues. J Med Virol. 2016;88(4):695-702.

25. Poluschkin L, Rautava J, Turunen A, Wang Y, Hedman K, Syrjänen K, et al. Polyomaviruses detectable in head and neck carcinomas. Oncotarget. 2018; 9(32):22642-52

26. Polz D, Morshed K, Stec A, Podsiadło Ł, Polz-Dacewicz M. Do polyomavirus hominis strains BK and JC play a role in oral squamous cell carcinoma? Ann Agric Environ Med. 2015;22(1):106-9.

27. Polz-Gruszka D, Morshed K, Jarzyński A, Polz-Dacewicz M. Prevalence of Polyoma BK virus (BKPyV), Epstein-Barr virus (EBV) and human papilloma virus (HPV) in Oropharyngeal Cancer. Pol J Microbiol. 2015;64(4):323-8.

28. Drop B, Strycharz-Dudziak M, Kliszczewska E, Polz-Dacewicz M. Coinfection with Epstein-Barr virus (EBV), human papilloma virus (HPV) and Polyoma BK virus (BKPyV) in laryngeal, Oropharyngeal and Oral cavity Cancer. Int J Mol Sci. 2017;18(12):2752.

29. Monaco MC, Jensen PN, Hou J, Durham LC, Major EO. Detection of JC virus DNA in human tonsil tissue: evidence for site of initial viral infection. J Virol. 1998:72(12):9918-23.

30. Kutsuna T, Zheng H, Abdel-Aziz HO, Murai Y, Tsuneyama K, Furuta I, et al. High JC virus load in tongue carcinomas may be a risk factor for tongue tumorigenesis. Virchows Arch. 2008;452(4):405-10.

31. Delbue S, Ferrante P, Provenzano M. Polyomavirus BK and prostate cancer: an unworthy scientific effort? Oncoscience. 2014;1(4):296-303.

32. Ksiaa F, Allous A, Ziadi S, Mokni M, Trimeche M. Assessment and biological significance of JC polyomavirus in colorectal cancer in Tunisia. J BUON. 2015;20(3):762-9.

33. Martel-Jantin C, Filippone C, Tortevoye P, Afonso PV, Betsem E, DescorpsDeclere $\mathrm{S}$, et al. Molecular epidemiology of merkel cell polyomavirus: evidence for geographically related variant genotypes. J Clin Microbiol. 2014;52(5):1687-90.

34. Vazquez-Guillen JM, Palacios-Saucedo GC, Rivera-Morales LG, AlonzoMorado MV, Burciaga-Bernal SB, Montufar-Martinez M, Ortiz-Lopez R, Gonzalez-Villasana V, Martinez-Torres AC, Serna-Hernandez JC, HernandezMartinez SJ, Castelan-Maldonado EE, Zavala-Pompa A, Montalvo-Bañuelos MS, Garcia-Cabello R, Sanchez-Fresno EC, Rodriguez-Padilla C. Infection and coinfection by human papillomavirus, Epstein-Barr virus and Merkel cell polyomavirus in patients with squamous cell carcinoma of the larynx: a retrospective study. Peer J. 2018;6:e5834. https://doi.org/10.7717/peerj.5834.

\section{Publisher's Note}

Springer Nature remains neutral with regard to jurisdictional claims in published maps and institutional affiliations. 